\title{
Correction to: Spatial and seasonal variations of radiocesium concentrations in an algae-grazing annual fish, ayu Plecoglossus altivelis collected from Fukushima Prefecture in 2014
}

\author{
Daigo Morishita ${ }^{1,4} \cdot$ Toshihiro Wada $^{2} \cdot$ Takuji Noda $^{3} \cdot$ Atsushi Tomiya $^{1,5} \cdot$ Masahiro Enomoto $^{1,6} \cdot$ Toshiyuki Sato $^{1,4}$. \\ Shunji Suzuki ${ }^{1,4} \cdot$ Gyo Kawata $^{1,6}$
}

Published online: 28 February 2019

(c) Japanese Society of Fisheries Science 2019

\section{Correction to: Fisheries Science \\ https://doi.org/10.1007/s12562-018-1280-8}

In the original publication the caption of Fig. $6 \mathrm{a}$ and $6 \mathrm{~b}$ is incorrectly published. The correct caption of Fig. $6 \mathrm{a}$ and $6 \mathrm{~b}$ should be read as "Linear relations between ${ }^{137} \mathrm{Cs}$ concentrations in body without head and internal organs and $\mathbf{a}^{137} \mathrm{Cs}$ concentrations in the head and internal organs or $\mathbf{b}{ }^{137} \mathrm{Cs}$ concentrations in whole body. Table 1 presents abbreviations. $X$ and $Y$ axes have logarithmic scales". The original article has been corrected.
Publisher's Note Springer Nature remains neutral with regard to jurisdictional claims in published maps and institutional affiliations.

The original article can be found online at https://doi.org/10.1007/ s12562-018-1280-8.

Toshihiro Wada

t-wada@ipc.fukushima-u.ac.jp

1 Fukushima Prefectural Inland Water Fisheries Experimental Station, Inawashiro, Fukushima 969-3283, Japan

2 Institute of Environmental Radioactivity, Fukushima University, Fukushima 960-1296, Japan

3 The Institute of Statistical Mathematics, Tachikawa, Tokyo 190-8562, Japan

4 Present Address: Fukushima Prefectural Fisheries and Marine Science Research Centre, Iwaki, Fukushima 970-0316, Japan

5 Present Address: Fishery Office of the Fukushima Prefectural Government, Iwaki, Fukushima 970-8026, Japan

6 Present Address: Fukushima Prefectural Research Institute of Fisheries Resources, Soma, Fukushima 976-0005, Japan 